\title{
HIV-1 envelope trimer elicits higher neutralizing antibody responses than monomeric gp120
}

\author{
JM Kovacs $^{1 *}$, JP Nkolola ${ }^{2}$, H Peng ${ }^{3}$, A Cheung ${ }^{4}$, J Perry ${ }^{4}$, CA Miller ${ }^{4}$, MS Seaman ${ }^{4}$, D Barouch² ${ }^{2}$ B Chen ${ }^{1}$ \\ From AIDS Vaccine 2012 \\ Boston, MA, USA. 9-12 September 2012
}

\section{Background}

HIV-1 envelope glycoprotein is the primary target for HIV1 -specific antibodies. The native HIV-1 envelope spike on the virion surface is a trimer, but trimeric gp140 and monomeric gp120 are currently believed to induce comparable immune responses. Indeed, most studies on the immunogenicity of HIV-1 envelope oligomers have revealed only marginal improvement over monomers. We report here that stable and homogenous envelope trimers with characteristics expected for the native viral spikes are substantially superior at eliciting neutralizing antibodies in guinea pigs.

\section{Methods}

Stable envelope gp140 trimer derived from clinical isolate sequences were stabilized with the T4-fibritin C-terminal trimerization tag and produced in stablely transfected 293 T cells. Characterization of Env trimers was performed by Western blotting, size-exclusion chromatography (SEC), analytical-ultra centrifugation (AUC), multi-angle light scattering (MALS) and surface plasmon resonance (SPR). Guinea pigs were immunized six times with $100 \mu \mathrm{g}$ of protein trimer or monomer in CpG/Emulsigen adjuvants. Antibody responses were determined by ELISA and TZM.bl neutralizing antibody assays.

\section{Results}

Homogeneous trimer and monomer preparations exhibited high purity as measured by SEC and SDS-PAGE. AUC and MALS analyses revealed expected molecular weight for both trimer and monomer. SPR analyses revealed expected binding with CD4 and multiple broadly neutralizing antibodies. These trimers have markedly different antigenic properties than those of monomeric gp120s derived from the same sequences. They induce potent, cross-clade neutralizing antibody responses with

${ }^{1}$ Harvard Medical School and Children's Hospital Boston, Boston, MA, USA Full list of author information is available at the end of the article titers substantially higher than those elicited by the corresponding gp120 monomers for a diverse set of both tier 1 and tier 2 viruses.

\section{Conclusion}

We have demonstrated the importance of generating highquality envelope trimers for antigenic and immunogenic studies; furthermore these results highlight the immunologic differences between monomers and high-quality envelope trimers, illustrating important implications for HIV-1 vaccine development and immunogen selection in large clinical trials.

\section{Author details}

${ }^{1}$ Harvard Medical School and Children's Hospital Boston, Boston, MA, USA. ${ }^{2}$ Beth Israel Deaconess Medical Center and Ragon Institute, Boston, MA, USA. ${ }^{3}$ Children's Hospital Boston, Boston, MA, USA. ${ }^{4}$ Beth Israel Deaconess Medical Center, Boston, MA, USA.

Published: 13 September 2012

doi:10.1186/1742-4690-9-S2-062

Cite this article as: Kovacs et al.: HIV-1 envelope trimer elicits higher neutralizing antibody responses than monomeric gp120. Retrovirology 2012 9(Suppl 2):O62.

Submit your next manuscript to BioMed Central and take full advantage of:

- Convenient online submission

- Thorough peer review

- No space constraints or color figure charges

- Immediate publication on acceptance

- Inclusion in PubMed, CAS, Scopus and Google Scholar

- Research which is freely available for redistribution

\section{Biomed Central}

